\title{
Monophasic pulse pair analysis of intracranial self-stimulation loci
}

\author{
RICHARD J. BODNAR, SOLOMON S. STEINER, JANE M. HEALEY \\ JEFFREY HALPERIN, and STEVEN J. ELLMAN \\ Department of Behavioral Physiology, N. Y.S. Psychiatric Institute, New York, New York 10032 \\ and City College of New York, New York, New York 10031
}

\begin{abstract}
Monophasic pulse pair stimulation, traditionally used to determine the refractory characteristics of peripheral nervous system neurons, has been modified for the same purpose in intracranial self-stimulation (ICSS) behavior. When the interval between pulses in a pair (C-T interval) is systematically varied, ICSS response rates change as a function of this variation. The present study evaluated alterations in the C-T interval/ICSS response rate function across ICSS loci and across stimulation conditions. Diencephalic sites supported peak ICSS responding at significantly shorter C-T intervals than met-mesencephalic or telencephalic sites. Despite previously cited differences in ICSS behavior observed within diencephalic and within met-mesencephalic loci, no differences in ICSS responding across C-T intervals were observed within diencephalic and met-mesencephalic sites. Moreover, diencephalic sites produced peak ICSS responding at shorter C-T intervals when cathodal and anodal sources were distant than when they were adjacent; the relative proximity of cathodal and anodal sources did not affect met-mesencephalic ICSS behavior. These results suggest that alterations in ICSS responding across C-T intervals are due to differences in the locus and density of ICSS neurons in the cathodal field and the presence and/or absence of adjacent anodal influences as well as the refractory characteristics of the ICSS neurons.
\end{abstract}

The monophasic stimulation technique was initially employed to determine the refractory characteristics of peripheral nervous system neurons (Erlanger \& Gasser, 1937; Lloyd, 1946; Sherrington, 1906). A pair of brief $(0.1 \mathrm{msec})$ monophasic rectangular electrical pulses, the first of which was designated the $C$ pulse and the second, the $\mathrm{T}$ pulse, would be temporally varied with respect to one another (C-T interval) during stimulation of peripheral nerves, allowing the estimation of their conduction velocity and axonal refractory periods.

Deutsch (1964) modified this basic technique in order to approximate the refractory characteristics of the neurons subserving intracranial self-stimulation (ICSS) behavior. Since ICSS behavior could not be sustained by delivery of single pulse pairs as the reinforcer, Deutsch had to use trains of the monophasic pulse pair stimulation with the temporal distance between succeeding pulse pairs designated the C-C interval. To determine refractory period estimations, Deutsch varied stimulus intensities so that $\mathrm{C}$-C stimulation ( $\mathrm{T}$ pulses omitted) supported minimal ICSS rates while the same stimulus parameters with the $\mathrm{T}$ pulses spaced midway between the $\mathrm{C}$ pulses (i.e.,

Research supported by CUNY FRAP Grant 1186 to S.J.E. and a NIDA grant to S.S.S. Manuscript preparation supported by NYS HRC Grant 922 to R.J.B. We thank Dr. R.F. Ackermann for helpful advice. Address all correspondence to: Dr. R.J. Bodnar, Department of Behavioral Physiology, New York State Psychiatric Institute, 722 West 168 Street, New York, New York 10032.
C-C interval, $10 \mathrm{msec}$; C-T interval, $5 \mathrm{msec}$ ) yielded consistent ICSS response rates. Then, while holding the C-C interval constant, variation of the C-T interval was found to produce variation in the animal's ICSS behavior. C-T intervals shortened below a critical value (0.8-1.2 msec) supported ICSS behavior similar to that of $\mathrm{C}-\mathrm{C}$ stimulation alone ( $\mathrm{T}$ pulses omitted), suggesting that at short $\mathrm{C}-\mathrm{T}$ intervals the $\mathrm{T}$ pulses were rendered ineffective. A number of subsequent studies verified this result (Gallistel, 1969, 1973; German \& Holloway, 1972; Szabo, Lenard, Kosaras, 1974; Yeomans, 1975). Further studies demonstrated that the current necessary to support a criterion ICSS rate was significantly increased as the C-T interval was shortened below this same critical value, indicating that the limitations of these intervals were not responsedependent (Coons, Smith \& Ungerleider, 1976; Rolls, 1971a; Smith \& Coons, 1970). These reductions in ICSS behavior were inferred to represent the refractory limitations of the axonal elements supporting ICSS behavior situated beneath the electrode tip. Electrophysiological support for this hypothesis included the demonstration that brainstem units, antidromically activated by hypothalamic ICSS, would respond to both pulses of a pulse pair when the C-T interval was greater than $0.8-1.1 \mathrm{msec}$, but would only respond to the $\mathrm{C}$ pulses when the C-T interval was reduced below that value (Gallistel, Rolls, \& Greene, 1969; Matthews \& Gallistel, 1975; Rolls, 1971b, 1971c). These data comprised the theoretical basis for the observation that 
all ICSS behavior could be described in terms of axonal determinants of reward and drive subserving the behavior (Deutsch, 1964; Gallistel, 1973).

However, these data have been almost exclusively derived from medial forebrain bundle (MFB) ICSS placements. One study investigating non-MFB ICSS placements reported that preoptic hypothalamic ICSS sites recovered consistent ICSS responding at a longer C-T interval than MFB placements (German \& Holloway, 1972). In contrast, Deutsch (1964) and Yeomans (1975) failed to find any C-T interval differences between ventral tegmental and MFB placements. Finally, Rolls (1971c) reported that in contrast to MFB stimulation, nucleus accumbens placements directly excited very few brainstem units.

If ICSS behavior is subserved by a neurophysiologically homogeneous system, and if pulse pair responsivity limitations are due exclusively to refractory characteristics, then limitations in ICSS behavior at short C-T intervals should occur uniformly across loci. To test this hypothesis, the present study investigated the responsivity across a range of C-T intervals for a variety of met-mesencephalic, diencephalic, and telencephalic ICSS loci, including the dorsal pontine tegmentum, the midbrain periaqueductal gray, the MFB, the perifornical area, the dorsal and far-lateral hypothalamic area, the septum, and the nucleus accumbens. In addition, each electrode locus was tested either with monopolar or bipolar stimulation across animals, since hypothalamic sites have been shown to recover peak ICSS response rates at shorter C-T intervals for monopolar than for bipolar stimulation (Bodnar, Steiner, Brutus, Ippolito, \& Ellman, 1978).

\section{METHOD}

Fifty-five male albino Holtzman Sprague-Dawley rats (350$500 \mathrm{~g}$ ), anesthetized with Chloropent (Fort Dodge Laboratories; $1 \mathrm{ml} / \mathrm{kg}$ ), were stereotaxically (Kopf Instruments) implanted with bipolar efectrodes (Plastic Products), aimed at two of the following brain areas: dorsal pontine tegmentum (DPT), midbrain periaqueductal gray (MPG), hypothalamus (HYP), and septum or nucleus accumbens. Each bipolar electrode was insulated except at the tips, which were aligned mediolaterally perpendicular to the midsaggital plane; each tip was separated from the other by a maximum of $0.3 \mathrm{~mm}$. Two stainless steel cortical screws were attached to the skull and electrically connected to an electrode plug. These screws, which were randomly assigned placement on the skull, could each serve as separate anodal indifferents. With the incisor bar set at $-5 \mathrm{~mm}$, DPT electrode coordinates were $1.5-2.0 \mathrm{~mm}$ posterior to the lambda intersection, $1.0 \mathrm{~mm}$ lateral to a line extrapolated from the sagittal suture, and $7.0 \mathrm{~mm}$ from the top of the skull. MPG electrode coordinates were $0.6-1.0 \mathrm{~mm}$ anterior to the lambda intersection, $1.5 \mathrm{~mm}$ lateral to the sagittal suture, $6.8-7.5 \mathrm{~mm}$ from the top of the skull, and inserted at a $12^{\circ}$ angle to the midsagittal plane. HYP coordinates were $4.2-4.4 \mathrm{~mm}$ posterior to the bregma intersection, $1.2-1.7 \mathrm{~mm}$ lateral to the sagittal suture, and $8.7 \mathrm{~mm}$ from the top of the skull. Septal coordinates were on the bregma intersection, $0.3 \mathrm{~mm}$ lateral to the sagittal suture and $6.4 \mathrm{~mm}$ from the top of the skull.
Ten days after surgery, each animal at each electrode site was shaped to barpress for brain stimulation in an operant conditioning chamber on a continuous reinforcement schedule. Reinforcements were $700 \mathrm{msec}$ trains of negatively going, capacitance-coupled, monophasic rectangular pulses of electrical stimulation delivered to an animal's electrode site. Any responses made during a stimulation train were ineffective. The stimulator was constructed from Digi-Bit solid state logic circuitry (BRS/ LVE) which allowed the experimenter to set the pulse duration $(0.1 \mathrm{msec})$ and the C-C interval $(20$ or $30 \mathrm{msec})$ and independently manipulate whether or not the $\mathrm{T}$ pulses were delivered, and if delivered, the C-T interval. Wave form, C-C interval, stimulus intensity, and pulse and train durations were continuously monitored by observing on a cathode ray oscilloscope the voltage drop across a $100-\Omega$ resistor in series with the animal.

Animals were shaped for a maximum of 15 daily sessions at each electrode site; the pole of each bipolar electrode which elicited the higher response rate in preliminary testing served as the cathode. Then, for each electrode site, the lowest intensity was chosen which yielded consistently high response rates at a C-T interval of $5.0 \mathrm{msec}$, but only operant responding, defined as less than 10 responses/min, if the $T$ pulses were omitted. The criterion intensities across animals varied from 200 to $600 \mu \mathrm{A}$, which are comparable to or lower than intensities used in other studies employing monophasic pulse pairs of brief 0.1-msec duration (Deutsch, 1964; Gallistel, 1969; German \& Hollway, 1972; Rolls, 1971a; Smith \& Coons, 1970; Szabo \& Milner, 1973). The number of microcoulombs (stimulation delivered per unit time) delivered in this stimulation technique is substantially less than that delivered by traditional $60-\mathrm{Hz}$ sinusoidal stimulation.

After preliminary testing, each animal barpressed for daily stimulation to an electrode site during a 72-min session, which was divided into nine 7-min periods. A 1 -min time-out occurred between each period, during which the C-T interval was changed. Eight C-T intervals $(0.5,0.8,1.0,1.2,1.5,2.0,3.0$, and $5.0 \mathrm{msec}$ ) and a condition in which the $\mathrm{T}$ pulses were omitted were randomly presented on each of the 9 days in a Latin square design. The mean response rate over the last $5 \mathrm{~min}$ of each 7 -min period constituted the dependent variable. Data from the first $2 \mathrm{~min}$ of each 7-min period were excluded from the analysis of experimental effects, but revealed that the Latin square design adequately controlled for order and carryover effects. The Latin square was constructed such that: (1) each stimulation condition occupied each ordinal position of the square only once over the 9-day procedure, and (2) each stimulation condition preceded each other stimulation condition only once over the 9-day procedure. If an animal had a second operational ICSS electrode site, the same paradigm was repeated in identical fashion for the second site.

C-T interval/response rate functions, averaged over the 9-day paradigm, were determined in different electrode sites across animals in one of two stimulation conditions: (1) when one pole of the bipolar electrode served as cathode and the other pole served as anode through the entire period of stimulation (bipolar condition), and (2) when one pole of the bipolar electrode served as cathode and a cortical screw served as anode (monopolar condition).

After completion of the experiment, all animals were overdosed with Chloropent and perfused through the heart with normal saline followed by $10 \%$ Formalin. Serial frozen sections were stained with luxol fast blue and cresyl violet (Klüver \& Barrera, 1953) and electrode loci were determined by microscopic examination of the sections.

\section{RESULTS}

Ninety-three electrode sites in 49 animals supported ICSS behavior at criterion levels; that is, the chosen 


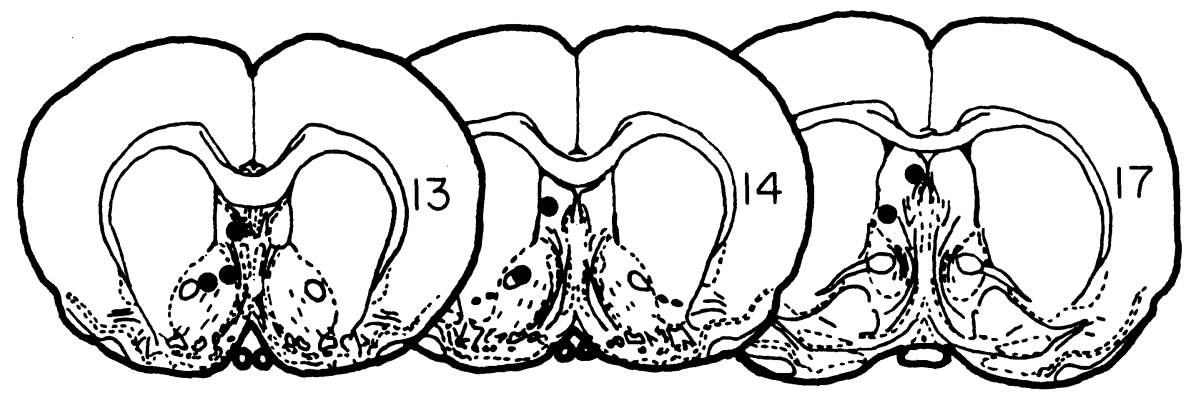

Figure 1. Schematic representation of the seven telencephalic electrode placements. The sections were derived from König and Klippel (1963).

intensity for each site supported consistently high (range: $20-120$ responses/min) response rates at a C-T interval of $5.0 \mathrm{msec}$, yet supported response rates that were always less than 10 responses/min when the $\mathrm{T}$ pulses were omitted. No significant differences in ICSS response rates when the T pulses were omitted were observed across sites or across stimulation conditions. Also, the criterion intensities did not significantly differ either among sites or between stimulation conditions. Figure 1 displays the seven electrode sites located in telencephalic structures, including the lateral and medial septum and nucleus accumbens. Figure 2 displays the 49 electrode sites located in diencephalic structures, including the MFB, fornix, internal capsule, $\mathrm{H}_{2}$ fields of Forel, and dorso-medial, periventricular, and ventro-medial HYP nuclei. Figure 3 displays the 37 electrode sites located in met-mesencephalic structures, including the locus coeruleus (LC), the dorsal noradrenergic bundle, the parabrachial nucleus of the fifth nerve, the brachium conjunctivum and MPG, which specifically included the Edinger-Westphal nuclei, the oculomotor nuclei, the dorsal and ventral tegmental decussations, the nucleus linearis, and the medial longitudinal fasciculus.

To determine the relative effectiveness of the $T$ pulses at different $\mathrm{C}$-T intervals, response rates elicited when the $T$ pulses were omitted were subtracted from response rates elicited at each of the $\mathrm{C}-\mathrm{T}$ intervals (T-pulse response rate). Then, each $\mathrm{T}$-pulse response rate at each $\mathrm{C}$ - $\mathrm{T}$ interval was expressed as a percentage of the $\mathrm{T}$-pulse response rate elicited at a $\mathrm{C}$ - $\mathrm{T}$ interval of $5.0 \mathrm{msec}$. This transformation was done to reduce the variance of peak ICSS responding found both within and across loci, and allowed the determination of the contribution of the T pulses to ICSS behavior at each C-T interval for each site.

A two-way analysis of variance was performed which analyzed the electrode locus and stimulation condition as one main effect and the contribution of $\mathrm{T}$ pulses at each $\mathrm{C}$-T interval as the second main effect. The relative contribution of $\mathrm{T}$ pulses to ICSS responding was significantly different across C-T intervals $[F(7,588)=142.3$, $\mathrm{p}<.001]$, across ICSS loci $[\mathrm{F}(8,84)=29.6, \mathrm{p}<.001]$, and for the interaction between electrode locus and C-T interval $[F(56,588)=39.9, \quad p<.001] . \quad$ A posteriori Scheffé comparisons were made, as applicable, to determine the differential responsivity of: (1) telencephalic, diencephalic, and met-mesencephalic areas in the monopolar condition; (2) sites within the diencephalic area in the monopolar condition; (3) sites within the metmesencephalic area in the monopolar condition; (4) diencephalic placements across monopolar and bipolar conditions; and (5) met-mesencephalic placements across monopolar and bipolar conditions.

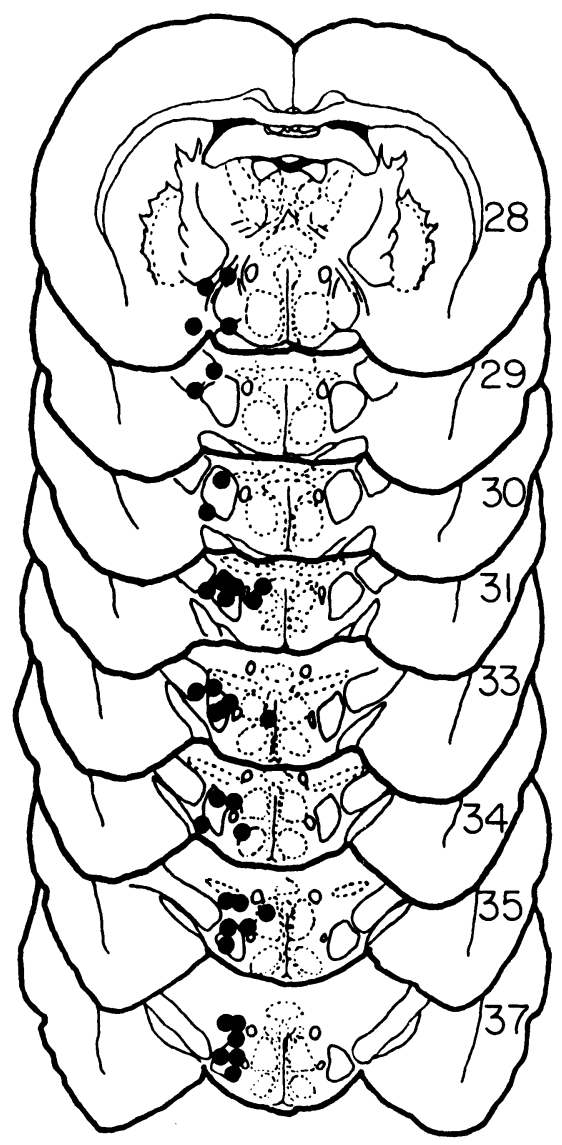

Figure 2. Schematic representation of the 49 diencephalic electrode placements; considerable overlap precluded the delineation of every localization. The sections were derived from König and Klippel (1963). 

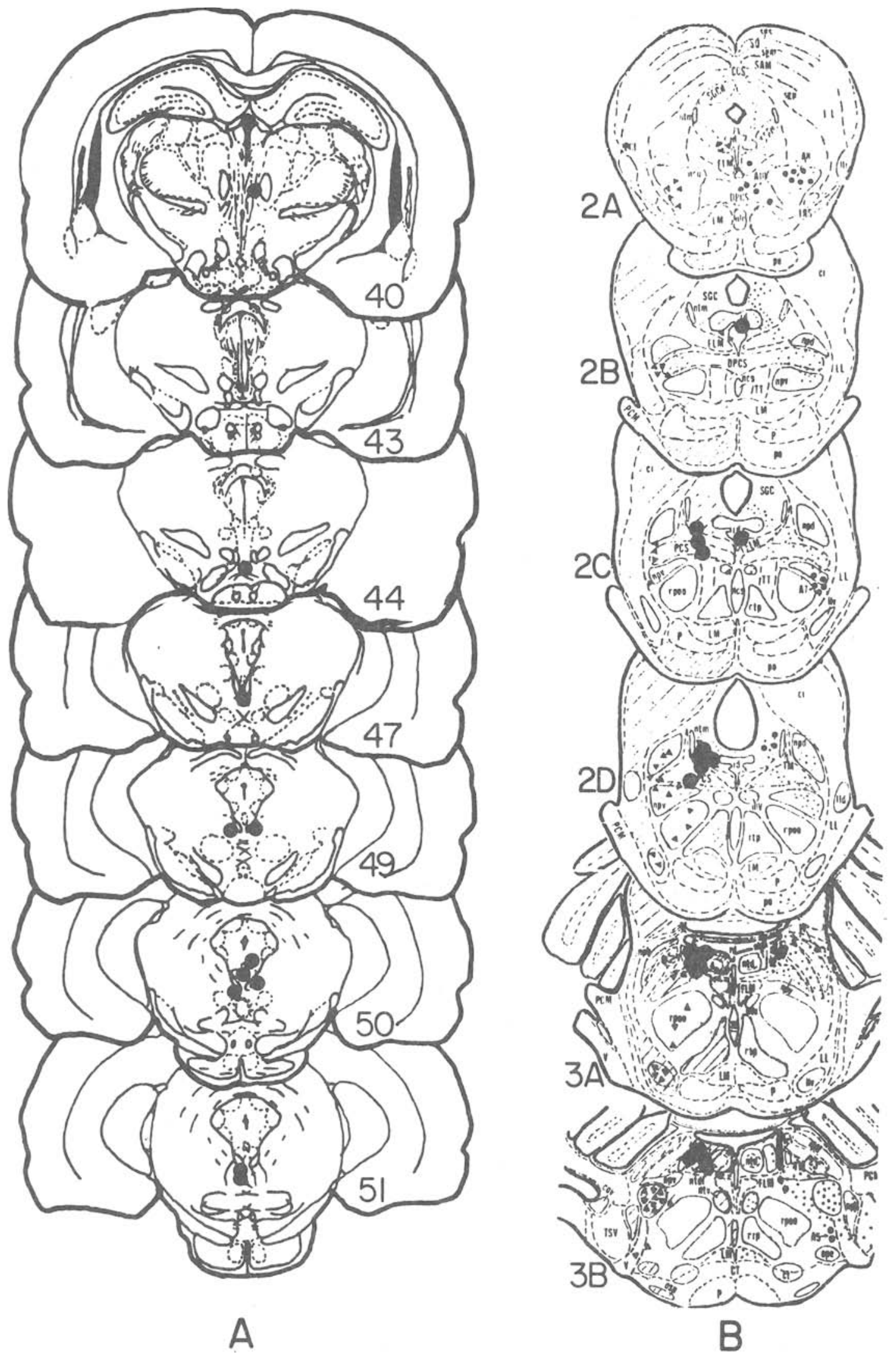

Figure 3. Schematic representation of the 37 met-mesencephalic electrode placements; considerable overlap precluded the delineation of every localization. The sections in the A column were derived from König and Klippel (1963), while the sections in the B column were derived from Palkovits and Jacobowitz (1974). 
ICSS C-T Responsivity Across Subcortical Areas

Forty-eight electrode sites tested in the monopolar condition were included in this analysis; 7 were located in telencephalic structures, 20 were in diencephalic structures, and 21 were in met-mesencephalic structures. Figure 4 displays the significant differences across brain areas in the relative contributions to ICSS responding across C-T intervals. No differences were noted across areas at a C-T interval of $0.5 \mathrm{msec}$, with ICSS rates varying between only $11 \%$ and $22 \%$ of peak responding. However, the contribution of the T pulses to ICSS responding differed significantly across brain areas for the C-T intervals of $0.8 \mathrm{msec}[\mathrm{F}(2,45)=4.80$, $\mathrm{p}<.05], 1.0 \mathrm{msec}(\mathrm{F}=5.41, \mathrm{p}<.01)$, and $1.2 \mathrm{msec}$ $(F=4.83, p<.05)$. No significant differences were noted at longer C-T intervals.

The ability of $\mathrm{T}$ pulses to generate peak ICSS responding at short C-T intervals was facilitated most at diencephalic loci, and followed by met-mesencephalic, and telencephalic loci, in that order. Diencephalic sites supported significantly greater ICSS responding than did telencephalic sites at C-T intervals of $0.8 \mathrm{msec}$ $[F(1,26)=6.44, \quad p<.05], \quad 1.0 \mathrm{msec} \quad(F=13.14$, $\mathrm{p}<.01)$, and $1.2 \mathrm{msec}(\mathrm{F}=25.98, \mathrm{p}<.01)$ and than did met-mesencephalic sites at C-T intervals of $0.8 \mathrm{msec}$ $[\mathrm{F}(1,40)=4.93, \mathrm{p}<.05]$ and $1.0 \mathrm{msec}(\mathrm{F}=4.18$, $\mathrm{p}<.05$ ). In turn, met-mesencephalic sites supported significantly greater ICSS responding than telencephalic sites at the C-T interval of $1.2 \mathrm{msec}[\mathrm{F}(1,25)=4.23$, $\mathrm{p}<.05]$. While diencephalic and met-mesencephalic sites each attained $90 \%$ of peak ICSS responding by a $\mathrm{C}$-T interval of $1.5 \mathrm{msec}$, telencephalic sites only reached that level by a C-T interval of $3.0 \mathrm{msec}$. The increased effectiveness of the $T$ pulses at short $C$ - $T$ intervals in diencephalic sites over met-mesencephalic sites could be most readily observed in the significant differences between the intercepts $[F(1,39)=8.59, \mathrm{p}<.01]$, but not the slopes $[F(1,39)=0.96]$ of linear regression

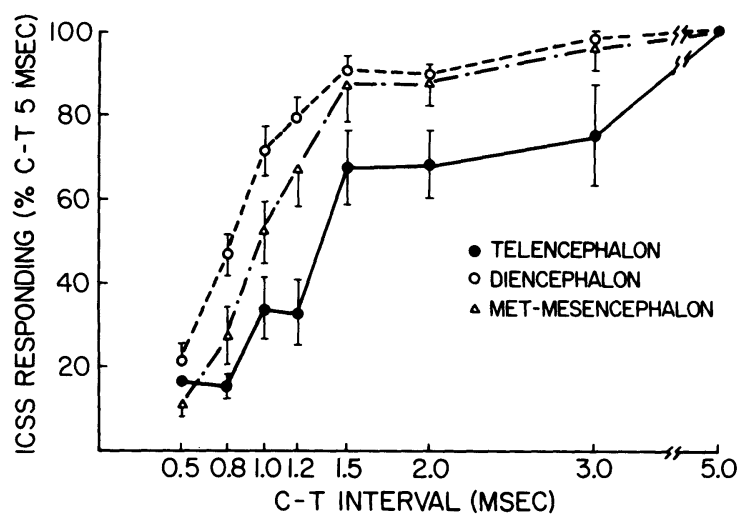

Figure 4. Mean T-pulse ICSS responsivity expressed as a percentage $( \pm$ S.E.M.) of ICSS responsivity at a C-T interval of $5.0 \mathrm{msec}$ for telencephalic $(n=7)$, diencephalic $(n=20)$, and met-mesencephalic $(n=21)$ loci. All animals were tested in the monopolar condition.

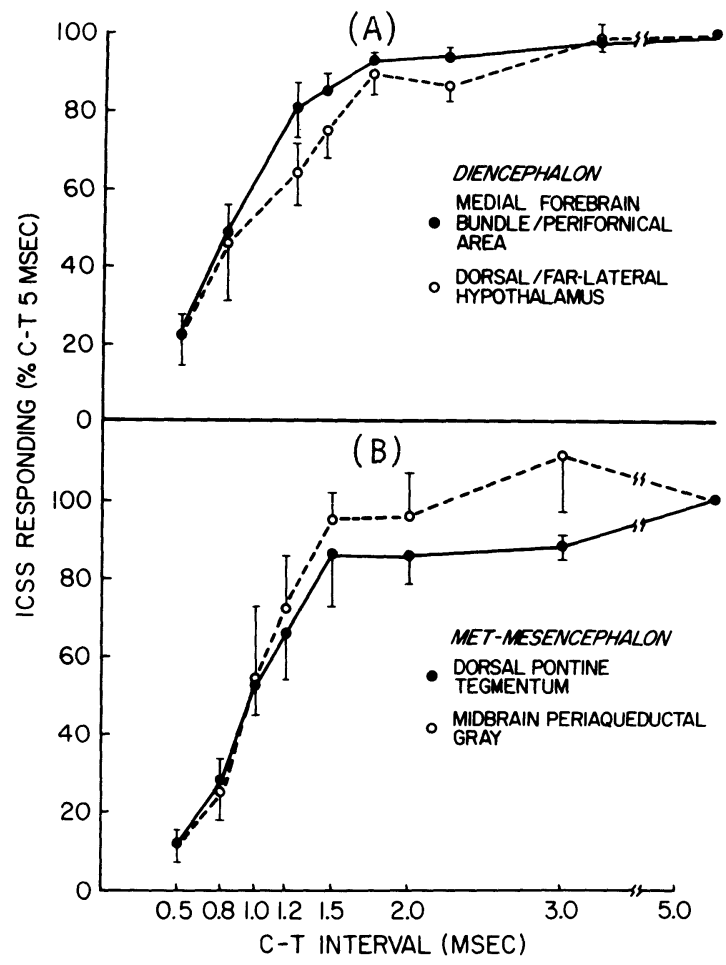

Figure 5. Mean T-pulse ICSS responsivity expressed as a percentage ( \pm S.E.M.) of ICSS responsivity at a $C$-T interval of 5.0 msec for: (A) diencephalic and (B) met-mesencephalic loci. In A, 9 MFB/perifornical placements and 11 dorsal/far-lateral HYP placements were compared in the monopolar condition. In B, 16 DPT placements and 5 MPG placements were compared in the monopolar condition.

equations for the respective ICSS loci. Between the C-T intervals of 0.5 and $1.5 \mathrm{msec}$, diencephalic sites showed a linear regression equation of $\mathrm{y}=.706 \mathrm{x}-.088$, while met-mesencephalic sites showed a linear regression equation of $\mathrm{y}=.797 \mathrm{x}-.304$.

\section{ICSS C-T Responsivity Within Diencephalic Loci}

MFB/perifornical and dorsal/far-lateral HYP ICSS sites have been shown to respond differentially to lesion, pharmacological, and interaction manipulations (Bodnar, Ellman, Ackermann, Greenblatt, Steiner, \& Coons, 1975; Farber, Ellman, Mattiace, Holtzman, Ippolito, Halperin, \& Steiner, 1976; Herberg, Stephens, \& Franklin, 1976; Stephens \& Herberg, 1975; Porrino \& Coons, Note 1). However, no differences in ICSS responding at any C-T interval were observed in comparing $9 \mathrm{MFB} /$ perifornical placements and $11 \mathrm{dorsal} /$ far-lateral HYP placements. Figure 5A shows that both types of placements reached $90 \%$ peak responding by the C-T interval of $1.5 \mathrm{msec}$.

ICSS C-T Responsivity Within Met-Mesencephalic Loci

DPT and MPG ICSS sites have been shown to respond differentially to lesion, pharmacological, and interaction manipulations (Clavier \& Corcoran, 1976; Ellman, 
Ackermann, Bodnar, Jackler, \& Steiner, 1976; Liebman \& Segal, 1977; Phillips, Brooke, \& Fibiger, 1975; Phillips \& Fibiger, 1973; Bodnar, Ackermann, Ippolito, Nelson, Healey, Brutus, Ellman, \& Steiner, Note 2). However, no differences in ICSS responding at any C-T interval were observed in comparing 16 DPT electrode sites and 5 MPG electrode placements. Figure 5B shows that both types of placements approached $90 \%$ of peak responding by the C-T interval of $1.5 \mathrm{msec}$.

\section{ICSS C-T Responsivity for Diencephalic Placements: Monopolar vs. Bipolar Stimulation}

Hypothalamic monopolar stimulation has been recently shown to be more effective in eliciting nearpeak ICSS responding at short C-T intervals than hypothalamic bipolar stimulation (Bodnar et al., 1978). This finding has been confirmed in the present results; Figure 6 displays these relationships for 29 diencephalic placements under bipolar stimulation and 20 diencephalic placements under monopolar stimulation. Monopolar delivery of the $\mathrm{T}$ pulses was significantly more effective in increasing ICSS responding at C-T intervals of $0.5 \mathrm{msec} \quad[\mathrm{F}(1,47)=4.47, \quad \mathrm{p}<.05], \quad 0.8 \mathrm{msec}$ $(\mathrm{F}=12.54, \mathrm{p}<.01), \quad 1.0 \mathrm{msec} \quad(\mathrm{F}=9.13, \mathrm{p}<.01)$, $1.2 \mathrm{msec}(\mathrm{F}=10.6, \mathrm{p}<.01)$ and $1.5 \mathrm{msec}(\mathrm{F}=7.38$, $\mathrm{p}<.01)$. Beyond $1.5 \mathrm{msec}$, no differences in ICSS responding were noted between the two conditions. Monopolar stimulation produced $70 \%$ of peak ICSS responding at a C-T interval of $1.0 \mathrm{msec}$ as compared to $1.5 \mathrm{msec}$ for bipolar stimulation.

\section{ICSS C-T Responsivity for Met-Mesencephalic}

\section{Placements: Monopolar vs. Bipolar Stimulation}

Figure 6 displays the effects of monopolar $(n=21)$ and bipolar $(\mathrm{n}=16)$ stimulation upon $\mathrm{C}$ - $\mathrm{T}$ responsivity for met-mesencephalic placements. In contrast to diencephalic loci, no significant differences in ICSS responsivity were noted between the two stimulation conditions at any C-T interval; both conditions produced $90 \%$ of peak responding by a C-T interval of $1.5 \mathrm{msec}$.

\section{DISCUSSION}

The present study clearly demonstrated that sitespecific and stimulation-specific differences exist in the relative contributions of $T$ pulses at various $C$ - $T$ intervals to produce peak ICSS responding. While telencephalic sites during monopolar stimulation needed long recovery time $(3.0 \mathrm{msec})$ to attain near-peak $(74 \%)$ response rates, recovery of near-peak ICSS responding at considerably shorter C-T intervals was noted for diencephalic (range: C-T 1.0; 71\%-1.5; 91\%) and metmesencephalic (range: C-T $1.2 ; 67 \%-1.5 ; 88 \%$ ) sites. Hence, though minimal ICSS responding in all three areas occurred at a C-T interval of $0.5 \mathrm{msec}(11 \%-22 \%$ peak), recovery of peak ICSS responding differentially

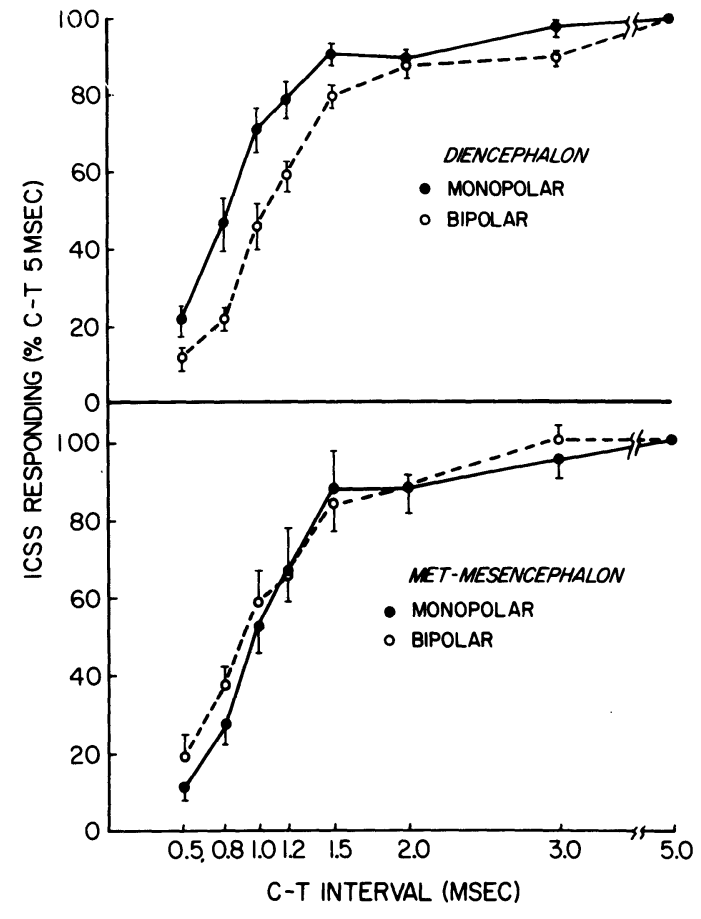

Figure 6. Mean T-pulse ICSS responsivity expressed as a percentage $( \pm$ S.E.M.) of ICSS responsivity at a C-T interval of $5.0 \mathrm{msec}$ as a function of monopolar $(n=20)$ and bipolar $(n=29)$ stimulation in diencephalic sites and as a function of monopolar $(n=21)$ and bipolar $(n=16)$ stimulation in metmesencephalic sites.

occurred across areas as a function of C-T interval. These differentiations were clearly specific to brain areas, rather than specific sites, since recovery to peak responding within diencephalic and met-mesencephalic loci were homogeneous. MFB and perifornical ICSS placements are differentially separable from dorsal and far-lateral HYP ICSS placements in reactivity to d-and 1 -amphetamine, in ICSS responding following LC lesions, and in supporting enhanced ICSS responding when paired with various metencephalic and mesencephalic ICSS loci (Bodnar et al., 1975; Farber et al., 1976; Herberg et al., 1976; Stephens \& Herberg, 1975; Porrino \& Coons, Note 1). Yet both sets of loci are similar in ICSS responding as a function of changes in C-T interval. Similarly, DPT ICSS placements are differentially separable from MPG ICSS placements in reactivity to d-and 1-amphetamine, in ICSS responding following forebrain lesions and in supporting enhanced ICSS responding when paired with various diencephalic ICSS loci (Bodnar et al., 1975; Clavier \& Corcoran, 1976; Ellman et al., 1976; Phillips et al., 1975; Phillips \& Fibiger, 1973; Bodnar et al., Note 2). Yet both sets of loci are similar in ICSS responding as a function of changes in C-T interval. Differences across ICSS areas' $\mathrm{C}-\mathrm{T} /$ response-rate functions were also noted across stimulation conditions. While monopolar stimulation elicited peak responding at shorter $\mathrm{C}$-T intervals than 
bipolar stimulation for diencephalic loci, no such differences were noted for met-mesencephalic loci.

Deutsch (1964) initially postulated that differences in ICSS responding as a function of C-T interval were due to the axonal refractory characteristics of ICSS neurons, just as this technique differentiated the temporal summation (Eccles, 1964; Lloyd, 1946), the refractory (Erlanger \& Gasser, 1937), and the latent addition (Lucas, 1910) characteristics of individual peripheral nervous system neurons. In support of these data, Rolls (1971 a) maintained that the absolute refractory period of ICSS neurons was less than a C-T interval of $0.6 \mathrm{msec}$, since the current necessary to support a predetermined criterion ICSS rate had to be increased to a maximal value when either the $\mathrm{T}$ pulses were omitted or when the C-T interval was less than $0.6 \mathrm{msec}$. The present data are in agreement with the latter estimate, since minimal ICSS behavior was produced at a C-T interval of $0.5 \mathrm{msec}$ for all sites. However, the suggestion that ail ICSS responding at short C-T intervals $(0.8-1.5 \mathrm{msec})$ was primarily due to axonal refractory period limitations seems to be at variance with the present results, since a refractory period hypothesis would necessarily predict that each ICSS locus and each stimulation condition should yield similar C-T interval/response rate functions. Alternative explanations have attributed these results to: (a) changes in the size of the ICSS cathodal stimulation field as a function of the stimulation locus and stimulation condition, and/or (2) the proximity of the anodal source to the cathodal stimulation site (Bodnar et al., 1978; Ranck, 1975).

In the first explanation, the ICSS stimulation field refers to the area which is directly activated by cathodal current; its size can be affected by changes in the distance between cathodal and anodal source. Since the distance between the two sources is greater in monopolar as compared to bipolar stimulation, the number of subsequent cathodal neural paths should hypothetically increase. If many neurons surrounding the electrode tip are responsible for ICSS behavior, then the increased effectiveness of monopolar stimulation should be dissipated. Our findings are consistent with this hypothesis. Each diencephalic locus tested in this study is surrounded by other ICSS loci, and under monopolar stimulation supported optimal ICSS rates at shorter C-T intervals than bipolar stimulation. Cathodal stimulation delivered to one HYP locus paired with a distant anodal source produces a resultant stimulation field which should encompass other HYP loci and, in turn, increase ICSS rates at those C-T intervals beyond absolute refractory period limitations. In contrast, monopolar stimulation delivered to met-mesencephalic loci elicited C-T functions similar to those elicited by bipolar stimulation. These data also conform to the stimulation field hypothesis since met-mesencephalic ICSS loci are relatively isolated. ICSS behavior is restricted to the
LC and mesencephalic $\mathrm{V}$ nuclei and their projections in the DPT and to areas laterally adjacent to and along a medial dorsal-ventral axis below the cerebral aqueduct in the MPG (Ackermann, Steiner, Bodnar, Jackler, Greenblatt, \& Ellman, 1977; Crow, 1972; Crow, Spear, \& Arbuthnott, 1972; Ellman, Ackermann, Bodnar, Jackler, \& Steiner, 1975; Ellman, Ackermann, Farber, Mattiace, \& Steiner, 1974; Liebman, Mayer \& Liebeskind, 1973; Margules, 1969; Ritter \& Stein, 1973; Steiner, Bodnar, Ackermann, \& Ellman, 1973). Cathodal stimulation delivered to one metmesencephalic locus paired with a distant anodal source should produce a resultant stimulation field in which a few ICSS-support neurons occupy the surround. Thus the advantage of the larger field would be nullified by the lack of ICSS loci occupying that field.

The size of the ICSS stimulation field activated by monopolar stimulation can also account for differences in C-T interval/response-rate functions across ICSS areas. Since current decreases an inverse square of the distance it travels (Kandel, 1976), the effectiveness of current to induce depolarization of a neuron should inversely vary with the distance between that neuron and the cathodal source. If the current value necessary to effect depolarization is relatively constant for all ICSS neurons, as has been suggested (Deutsch, 1964; Gallistel, 1973), then delivery of the C pulse of each pulse pair should depolarize all ICSS neurons in the stimulation field. Delivery of $\mathrm{T}$ pulses of each pulse pair $0.5 \mathrm{msec}$ thereafter would be rendered ineffective by the absolute refractory period incurred by the $\mathrm{C}$ pulses. However, delivery of $\mathrm{T}$ pulses of each pulse pair $0.8-1.2 \mathrm{msec}$ thereafter would hypothetically arrive during the relative refractory period. The current value necessary to effect depolarization in the relative refractory period is higher than that for the resting state (Curtis \& Cole, 1942; Hodgkin \& Huxley, 1939, 1945). Thus, the current value that was able to effect depolarization of distant ICSS neurons with the $C$ pulse cannot replicate this effect with the $T$ pulse, because both the increased relative refractory period threshold and the decrement in current effectiveness as a function of distance should preclude this neuron's reactivation. However, this diminution in responsivity is itself altered as a function of ICSS neuron density. High ICSS-density areas (HYP) are less affected by the current effectiveness as a function of distance, since these loci are adjacent to one another and the distance traversed in order to stimulate the necessary number of neurons to sustain behavior would be small. In contrast, lowdensity ICSS areas (septum, metencephalon/mesencephalon) are more susceptible to these limitations with responsivity concomitantly lower at short C-T intervals. Again, the results agree with this explanation. Diencephalic sites produced more near-peak ICSS rates at C-T intervals of 0.8 and $1.0 \mathrm{msec}$ than did either metmesencephalic or telencephalic sites. In turn, met- 
mesencephalic sites produced more near-peak ICSS rates than telencephalic sites at a C-T interval of $1.2 \mathrm{msec}$. The relative density of ICSS loci within each area is greatest for the tested diencephalic sites, less for the tested met-mesencephalic sites, and least for the tested telencephalic sites (see German \& Bowden, 1974), suggesting that the density of ICSS sites surrounding an electrode placement integrally affects the shape of its C-T function.

The proximity of anodal hyperpolarization in relation to the cathodal source should also affect C-T responsivity. The $C$ pulses of each pulse pair effect depolarization at the cathodal source and concomitantly produce hyperpolarization at the anodal source, thus increasing the depolarization threshold at the latter site. As in the present study's bipolar condition, when the hyperpolarized anodal field and the cathodal field overlap, the $T$ pulses of each pulse pair can potentially be delivered to a hyperpolarized field. Further, if the current value does not exceed the hyperpolarized neural threshold, the T pulse will fail to activate the ICSS neurons, which in turn would reduce the probability of ongoing ICSS behavior. This decrement should hypothetically coincide with the time course of the hyperpolarization, so, as the C-T interval increases, the probability that the $T$ pulses would encounter a hyperpolarized field should decrease. Again, the present data are in agreement with this hypothesis. The increased ability of monopolar stimulation to produce greater responding at short C-T intervals in diencephalic, but not met-mesencephalic, structures is explained by the greater density of potentially hyperpolarized ICSS neurons under bipolar stimulation in diencephalic areas. In contrast, bipolar stimulation in met-mesencephalic areas should hyperpolarize fewer ICSS neurons, since fewer ICSS neurons occupy the surround.

The present data indicate that ICSS responding as a function of C-T interval differs across subcortical areas, particulariy between the intervals of 0.8 and $1.5 \mathrm{msec}$. Clearly, these differences are not due solely to variations in the relative refractory periods of neurons subserving ICSS behavior, but are influenced by such factors as the density of the ICSS neurons in the stimulation field and the proximity of the anodal source. Recent pharmacological studies have argued further against the unitary explanation that the axonal refractory characteristics of ICSS neurons solely determine variations in $\mathrm{C}$ - $\mathrm{T}$ functions in that drugs affecting synaptic transmission concomitantly alter ICSS responsivity at these same C-T intervals (Coons et al., 1976; Nelson, Brutus, Wilson, Farrell, Ocheret, Ellman, \& Steiner, 1977). The present methodology cannot completely specify the contributions to alterations in C-T responsivity of each of the described mechanisms singly. However, further studies, perhaps employing the recently described strength-duration functions heretofore limited to hypothalamic and ventral tegmental placements, can explain each factor's precise role (Matthews, 1977; White, 1976; Yeomans, 1975; Yeomans \& Davis, 1975).

\section{REFERENCE NOTES}

1. Porrino, L., \& Coons, E. E. Time dependent inhibition of lateral hypothalamic reward. Presented at the Eastern Psychological Association, New York, 1975.

2. Bodnar, R. J., Ackermann, R. F., Ippolito, P. M., Nelson, W. T., Healey, J. M., Brutus, M., Ellman, S. J., \& Steiner, S. S. Directional neurophysiological interactions between brainstem and hypothalamic self-stimulation loci. Presented at the American Psychological Association, Washington, 1976.

\section{REFERENCES}

Ackermann, R. F., Steiner, S. S., Bodnar, R. J., Jackler, F., Greenblatt, E. R., \& Ellman, S. J. Characterization of selfstimulation elicited from rat dorsolateral periaqueductal gray. International Journal of Neuroscience, 1977, 7, 235-238.

Bodnar, R. J., Ackermann, R F., Ippolito, P. M., Nelson, W. T., Healey, J. M., Brutus, M., Ellman, S. J., \& STEINER, S. S. Directional neurophysiological interactions between brainstem and hypothalamic self-stimulation loci. Presented at the American Psychological Association, Washington, 1976.

Bodnar, R. J., Ellman, S. J., Ackermann, R. F., Greenblatt, E. R., STeiner, S. S., \& Coons, E. E. Directionality of neurophysiological interactions between brainstem and hypothalamic self-stimulation loci in rats. Society for Neuroscience (Abstract), 1975, 1, 431.

Bodnar, R. J., Steiner, S. S., Brutus, M., Ippolito, P. M., \& Ellman, S. J. Hypothalamic self-stimulation differs as a function of anodal locus. Physiological Psychology, 1978, 6, 48-52.

Clavier, R. M., \& Corcoran, M. E. Attenuation of selfstimulation from substantia nigra but not dorsal tegmental noradrenergic bundle by lesions of sulcal prefrontal cortex. Brain Research, 1976, 113, 59-70.

Coons, E. E., Smith, N., \& UNGerleider, L. G. Uses of double-pulse stimulation behaviorally to infer refractoriness, summation, convergence and transmitter characteristics of hypothalamic reward systems. Journal of Comparative and Physiological Psychology, 1976, 90, 317-342.

Crow, T. J. A map of the rat mesencephalon for electrical self-stimulation. Brain Research, 1972, 36, 265-273.

Crow, T. J., Spear, P. J., \& Arbuthnott, G. W. Intracranial self-stimulation with electrodes in the region of the locus coeruleus. Brain Research, 1972, 36, 275-287.

Curtis, H. J., \& Cole, K. S. Membrane resting and action potentials from the squid giant axon. Journal of Cellular and Comparative Physiology, 1942, 19; 135-144.

DEUTSCH, J. A. Behavioral measurement of the neural refractory period and application to intracranial self-stimulation. Journal of Comparative and Physiological Psychology, 1964, 58, 1-9.

ECCLEs, J. C. The physiology of synapses. Berlin: Springer-Verlag, 1964.

Ellman, S. J., Ackermann, R. F., Bodnar, R. J., Jackier, F., \& STEINER, S. S. Comparison of behaviors elicited by electrical brain stimulation in dorsal brainstem and hypothalamus of rats. Journal of Comparative and Physiological Psychology, 1975, 88, 816-828.

Ellman, S. J., \& Ackermann, R. F., Bodnar, R. J., Jackler, F., \& STEINER, S. S. D- and 1-amphetamine differentially mediates self-stimulation in rat dorsal midbrain area. Physiology \& Behavior, 1976, 16, 1-8.

Ellman, S. J., Ackermann, R. F., Farber, J., Mattiace, L. A., \& Steiner, S. S. Relationship between dorsal brainstem 
sleep sites and intracranial self-stimulation. Physiological Psychology, 1974, 2, 31-34.

ERLANGER, J., \& GASSER, H. S. Electrical signs of nervous activity. London: Oxford University Press, 1937.

Farber, J., Ellman, S. J., Mattiace, L. A., Holtzman, A., IPPOlito, P., Halperin, R., \& Steiner, S. S. Differential effects of unilateral dorsal hindbrain lesions on hypothalamic self-stimulation in the rat. Brain Research, 1976, 112, 148-155.

Gallistel, C. R. The incentive of brain-stimulation reward. Journal of Comparative and Physiological Psychology, 1969, 69, 713-721.

GALlistel, C. R. Self-stimulation: The neurophysiology of reward and motivation. In J. A. Deutsch (Ed.), The physiological basis of memory. New York: Academic Press, 1973.

Gallistel, C. R., Rolls, E. T., \& Greene, D. Neuron function inferred from behavioral and electrophysiological estimates of refractory period. Science, 1969, 166, 1028-1030.

German, D. C., \& Bowden, D. M. Catecholamine systems as the neural substrate for intracranial self-stimulation. Brain Research, 1974, 73, 381-419.

German, D. C., \& Holloway, F. A. Behaviorally determined neurophysiological properties of MFB self-stimulation fibers. Physiology \& Behavior, 1972, 9, 823-829.

HerberG, L. D., Stephens, D. N., \& Frankin, K. B. J. Catecholamines and self-stimulation: Evidence suggesting a reinforcing role for noradrenaline and a motivating role for dopamine. Pharmacology, Biochemistry and Behavior, 1976, 4, 575-582.

Hodgkin, A. L., \& Huxiey, A. F. Action potentials recorded from inside a nerve fiber. Nature, 1939, 144, 710-711.

Hodgkin, A. L., \& HuXIEY, A. F. Resting and action potentials in single nerve fibres. Journal of Physiology, 1945, 104, 176-195.

Kandel, E. R. Cellular basis of behavior. San Francisco: Freeman, 1976.

KLÜVER, H., \& BARRERA, E. A method for combined staining of cells and fibers in the nervous system. Journal of Neuropathology and Experimental Neurology, 1953, 12, 400-403.

KönIG, J. F. R., \& KLIPPEL, R. A. The rat brain. A stereotaxic atlas. Baltimore: Williams and Wilkins, 1963.

Liebman, J. M., MaYer, D. F., \& Liebeskind, J. C. Selfstimulation loci in the midbrain central gray matter of the rat. Behavioral Biology, 1973, 9, 299-306.

Liebman, J., \& SEGAL, D. S. Differential effects of morphine and d-amphetamine on self-stimulation from closely adjacent regions in rat midbrain. Brain Research, 1977, 136, 103-117.

LLOYD, D. P. C. Facilitation and inhibition of spinal motorneurons. Journal of Neurophysiology, 1946, 9, 421-438.

LuCAs, K. Quantitative researches on the summation of inadequate stimuli in muscle and nerve. Journal of Physiology, 1910, 39, 461-475.

MARGULES, D. L. Noradrenergic rather than serotonergic basis of reward in the dorsal tegmentum. Journal of Comparative and Physiological Psychology, 1969, 67, 32-35.

Matthews, G. Neural substrate for brain stimulation reward in the rat: Cathodal and anodal strength-duration response. Journal of Comparative and Physiological Psychology, 1977, 91, 858-874.

Matthews, G., \& Gallistel, C. R. Bilateral interactions in single units driven by MFB self-stimulation electrodes. Physiology \& Behavior, 1975, 15, 543-549.

Nelson, W. T., Brutus, M., Wilson, J. E., Farrell, R. A., Ocheret, D. R., Ellman, S. J., \& Steiner, S. S. Effect of morphine on intracranial self-stimulation in rats. Society for Neuroscience (Abstracts), 1977, 3, 298.

Palkovits, M., \& JAcoвowitz, D. M. Topographic atlas of catecholamine and acetylcholinesterase-containing neurons in the rat brain. II. Hindbrain (mesencephalon, rhombencephalon). Journal of Comparative Neurology, 1974, 157, 29-42.

Phillips, A. G., Brooke, S. M., \& Fibiger, H. C. Effects of amphetamine isomers and neuroleptics on self-stimulation from the nucleus accumbens and dorsal noradrenergic bundle. Brain Research, 1975, 85, 13-22.

Phillips, A. G., \& Fibiger, H. C. Dopaminergic and noradrenergic substrates of positive reinforcement: Differential effects of d- and l-amphetamine. Science, 1973, 179, 575-577.

RANCK, J. B. Which elements are excited in electrical stimulation of mammalian central nervous system: A review. Brain Research, 1975, 98, 417-440.

Ritter, S., \& Stein, L. Self-stimulation of noradrenergic cell group (A6) in locus coeruleus of rats. Journal of Comparative and Physiological Psychology, 1973, 85, 443-452.

Rolls, E. T. Absolute refractory period of neurons involved in MFB self-stimulation. Physiology \& Behavior, 1971, 7, 311-315. (a)

RolLs, E. T. Involvement of brainstem units in medial forebrain bundle self-stimulation. Physiology \& Behavior, 1971, 7, 297. 310. (b)

Rolls, E. T. Contrasting effects of hypothalamic and nucleus accumbens septi self-stimulation on brain stem single unit activity and cortical arousal. Brain Research, 1971, 31, 275-285.

ShERRINGTON, C. The integrative action of the nervous system. New Haven: Yale University Press, 1906.

SMITH, N., \& Coons, E. E. Temporal summation and refractoriness in hypothalamic reward neurons as measured by selfstimulation behavior. Science, 1970, 169, 782-785.

Steiner, S. S. Bodnar, R. J., Ackermann, R. F., \& Ellman, S. J. Escape from rewarding brain stimulation of dorsal brainstem and hypothalamus. Physiology \& Behavior, 1973, 11, 589-591.

Stephens, D. N., \& Herberg, L. J. Catecholamines and selfstimulation: Pharmacological differences between near- and farlateral hypothalamic sites. Brain Research, 1975, 90, 348-351.

Szabo, I., Lenard, L., \& Kosaras, B. Drive decay theory of self-stimulation: Refractory periods and axon diameters in hypothalamic reward loci. Physiology \& Behavior, 1974, 12, 329-343.

Szabo, I., \& Milner, P. M. Electrode tip alignment and selfstimulation: Influence of anodal hyperpolarization. Physiology \& Behavior, 1973, 11, 581-583.

WHITE, N. Strength-duration analysis of the organization of reinforcement pathways in the medial forebrain bundle of rats. Brain Research, 1976, 110, 575-591.

Yeomans, J. S. Quantitative measurement of neural poststimulation excitability with behavioral methods. Physiology \& Behavior, 1975, 15, 593-602.

Yeomans, J. S., \& Davis, J. K. Behavioral measurement of the post-stimulation excitability of neurons mediating selfstimulation by varying the voltage of paired pulses. Behavioral Biology, 1975, 15, 435-447.

(Received for publication December 28, 1977; revision accepted February 9, 1978.) 